OPEN ACCESS

Edited by:

Nicole Isbel,

Princess Alexandra Hospital, Australia

Reviewed by:

Rolf Bass,

Retired, Berlin, Germany

David A Vesey,

Princess Alexandra Hospital, Australia

*Correspondence:

Judith E. van Zanden

j.e.van.zanden@umcg.nl

Specialty section: This article was submitted to Inflammation Pharmacology,

a section of the journal

Frontiers in Pharmacology

Received: 24 July 2020 Accepted: 27 January 2021

Published: 22 February 2021

Citation:

Van Zanden JE, 'T Hart NA, Ottens PJ, Liu B, Rebolledo RA, Erasmus ME and

Leuvenink HGD (2021)

Methylprednisolone Treatment in Brain Death-Induced Lung Inflammation-A

Dose Comparative Study in Rats.

Front. Pharmacol. 12:587003.

doi: 10.3389/fphar.2021.587003

\section{Methylprednisolone Treatment in Brain Death-Induced Lung Inflammation-A Dose Comparative Study in Rats}

\author{
Judith E. Van Zanden ${ }^{1 *}$, Nils A. 'T Hart ${ }^{2}$, Petra J. Ottens ${ }^{1}$, Bo Liu ${ }^{1,3}$, Rolando A. Rebolledo ${ }^{1,4}$, \\ Michiel E. Erasmus ${ }^{5}$ and Henri G. D. Leuvenink ${ }^{1}$

\begin{abstract}
${ }^{1}$ Department of Surgery, University of Groningen, University Medical Center Groningen, Groningen, Netherlands, ${ }^{2}$ Department of Pathology, University of Groningen, University Medical Center Groningen, Groningen, Netherlands, ${ }^{3}$ Department of Neurosurgery, Tianjin Medical University General Hospital, Tianjin, China, ${ }^{4}$ Institute for Medical and Biological Engineering, Schools of Engineering, Biological Sciences and Medicine, Pontificia Universidad Católica de Chile, Santiago, Chile, ${ }^{5}$ Department of cardiothoracic surgery, University of Groningen, University Medical Center Groningen, Groningen, Netherlands
\end{abstract}

Background: The process of brain death $(\mathrm{BD})$ leads to a pro-inflammatory state of the donor lung, which deteriorates its quality. In an attempt to preserve lung quality, methylprednisolone is widely recommended in donor lung management. However, clinical treatment doses vary and the dose-effect relation of methylprednisolone on BD-induced lung inflammation remains unknown. The aim of this study was to investigate the effect of three different doses methylprednisolone on the BD-induced inflammatory response.

Methods: BD was induced in rats by inflation of a Fogarty balloon catheter in the epidural space. After $60 \mathrm{~min}$ of $\mathrm{BD}$, saline or methylprednisolone (low dose $(5 \mathrm{mg} / \mathrm{kg})$, intermediate dose $(12.5 \mathrm{mg} / \mathrm{kg})$ or high dose $(22.5 \mathrm{mg} / \mathrm{kg}))$ was administered intravenously. The lungs were procured and processed after $4 \mathrm{~h}$ of $\mathrm{BD}$. Inflammatory gene expressions were analyzed by RT-qPCR and influx of neutrophils and macrophages were quantified with immunohistochemical staining.

Results: Methylprednisolone treatment reduced neutrophil chemotaxis as demonstrated by lower IL-8-like CINC-1 and E-selectin levels, which was most evident in rats treated with intermediate and high doses methylprednisolone. Macrophage chemotaxis was attenuated in all methylprednisolone treated rats, as corroborated by lower MCP-1 levels compared to saline treated rats. Thereby, all doses methylprednisolone reduced TNF- $\alpha, \quad I L-6$ and IL- $1 \beta$ tissue levels. In addition, intermediate and high doses methylprednisolone induced a protective anti-inflammatory response, as reflected by upregulated IL-10 expression when compared to saline treated brain-dead rats.

Conclusion: We showed that intermediate and high doses methylprednisolone share most potential to target BD-induced lung inflammation in rats. Considering possible side effects of high doses methylprednisolone, we conclude from this study that an intermediate dose of $12.5 \mathrm{mg} / \mathrm{kg}$ methylprednisolone is the optimal treatment dose for 
BD-induced lung inflammation in rats, which reduces the pro-inflammatory state and additionally promotes a protective, anti-inflammatory response.

Keywords: brain death, lung donation, lung inflammation, methylprednisolone, donor management, dose comparison study, lung transplantation

\section{INTRODUCTION}

Despite developments in deceased after circulatory death (DCD) donation, donation after brain death (DBD) still serves as the major source for donor lungs (Cypel et al., 2015). In both DCD and DBD donors pathophysiological changes occur, which affect both quantity and quality of organs available for transplantation (Cooper et al., 1989; Neyrinck et al., 2013). Since only 30\% of donor lungs are considered suitable for transplantation, lungs seem highly susceptible to damage. In contrast, over $70 \%$ of the abdominal organs are procured and utilized for transplantation (Rahmel, 2013). One of the mechanisms that detrimentally affects lung quality in DBD donors is activation of the immune system, which aggravates rejection of organs after transplantation (Avlonitis et al., 2003).

From the onset of brain death (BD), inflammatory mediators such as TNF- $\alpha$, IL- $1 \beta$, IL- 6 and IL- 8 are released by the ischemic brain (Wang et al., 1994; Wang et al., 1995; Liu et al., 1993; Liu et al., 1994). Local inflammation and the direct effect of the insult itself cause disruption of the blood-brain-barrier and brain stem death. Along with local activation of the immune system in the brain, a systemic inflammatory response syndrome (SIRS) occurs (McKeating et al., 1997; Lu et al., 2009). The peripheral immune system is activated and pro-inflammatory cytokines are released from the spleen, which augments the inflammatory response (Offner et al., 2006). Eventually, the BD-induced immunological mechanisms lead to a pro-inflammatory state of the potential donor lung, which is associated with increased rejection rates of transplanted donor lungs (Zweers et al., 2004).

Most clinical guidelines recommend administration of methylprednisolone in brain-dead lung donors, to promote hemodynamic stability of the donor and improve lung function after transplantation (Cooper et al., 1988; Follette et al., 1998). These treatment regimens vary from fixed single doses of $1-5 \mathrm{~g}$ methylprednisolone, to weight-base doses ranging from 15-60 mg/kg methylprednisolone (Dupuis et al., 2014). The effect of varying doses methylprednisolone on the $\mathrm{BD}$-induced inflammatory status, has not been elucidated. The aim of this study was to investigate the effect of different doses methylprednisolone on the BD-induced inflammatory status of donor lungs. To this end, we subjected rats to $\mathrm{BD}$ and treated them with a low, intermediate or high dose methylprednisolone during donor management. We showed that an intermediate dose of $12.5 \mathrm{mg} / \mathrm{kg}$ methylprednisolone is the optimal treatment dose for BD-induced lung inflammation in rats.

\section{MATERIALS AND METHODS}

\section{Experimental Outline}

Rats were randomly assigned to one of four experimental groups (6-8 rats/group, Figure 1). BD was induced in all experimental groups, and $1 \mathrm{~h}$ after $\mathrm{BD}$ induction rats were treated intravenously with 1) $0.9 \%$ saline (control, $\mathrm{n}=7$ ), 2) low dose methylprednisolone ( $5 \mathrm{mg} / \mathrm{kg}$ of bodyweight (BW), $\mathrm{n}=6), 3$ ) intermediate dose methylprednisolone $(12.5 \mathrm{mg} / \mathrm{kg}$ of $\mathrm{BW}, \mathrm{n}=8)$ or 4) high dose methylprednisolone $(22.5 \mathrm{mg} / \mathrm{kg}$ of $\mathrm{BW}, \mathrm{n}=7)$. The various doses of methylprednisolone administration were defined based on previous pilot experiments, in which $22.5 \mathrm{mg} / \mathrm{kg}$ methylprednisolone was the maximum dose in which hemodynamic stability was maintained.

\section{Rats}

Male adult Fischer F344 rats (Harlan Netherlands B.V., Melderslo, The Netherlands) with a weight of 250-300 g were used. Rats received standard humane care in compliance with the Principles of Laboratory Animal Care (NIH Publication NO. 8623, revised 1985) and the Dutch Law on Experimental Animal Care. Permission to conduct this study was approved by the local animal committee, according to the Experiments on Animals Act (Animal Welfare Body Utrecht, 2017).

\section{Rat Brain Death Model}

BD was induced as previously described (Rebolledo et al., 2015). Rats were anesthetized by a mixture of $100 \% \quad \mathrm{O}_{2}$ and $5 \%$ isoflurane. The femoral vessels were cannulated to enable mean arterial pressure (MAP) measurements and fluid administration. Rats were tracheotomized, intubated with a $14 \mathrm{G}$ polyethylene tube and ventilated with tidal volumes of $2-3 \mathrm{ml} /$ stroke. Respiratory rate was titrated throughout the experiment to maintain end-tidal $\mathrm{CO}_{2}$ between $20-22 \mathrm{mmHg}$, with a minimum frequency of $50 / \mathrm{min}$ and a maximum frequency of $120 / \mathrm{min}$. Positive end-expiratory pressure (PEEP) was $1-1.5 \mathrm{~cm} \mathrm{H}_{2} \mathrm{O}$. Fraction of inspired oxygen ( $\mathrm{FiO} 2$ ) was 1 until 30 min after $\mathrm{BD}$ induction, after which $\mathrm{FiO}_{2}$ was reduced to 0.5. A frontolateral hole was drilled in the skull and a No. 4 balloon Fogarty catheter (Edwards Lifesciences Co, Irvine, CA) was inserted and inflated in the epidural space. Inflation of the balloon catheter induced initially a characteristic hypotensive period. When MAP returned to its basal level, inflation of the balloon catheter was ceased and anesthesia withdrawn. BD was confirmed by the absence of corneal and pupillary reflexes. Body temperature was maintained at $38^{\circ} \mathrm{C}$ with a heating pad and MAP was stabilized above $80 \mathrm{mmHg}$ during the BD period. In case of blood pressure drops, Hydroxyethyl starch (HAES-steril $100 \mathrm{~g} / \mathrm{L}$, Fresenius Kabi AG, Bad Hamburg, Germany) was administered in a bolus of $0.5 \mathrm{ml}$ with a maximum infusion rate of $1 \mathrm{ml} / \mathrm{h}$. In case of unresponsiveness to HAES, norepinephrine (NA, $0.01 \mathrm{mg} / \mathrm{ml}$, Eu Pharma, Almere, the Netherlands) infusions were added. One hour after BD induction, rats were treated with either $0.9 \%$ saline or a low, intermediate or high dose methylprednisolone $(40 \mathrm{mg} / \mathrm{ml}$, Pfizer, Capelle aan den IJssel, 

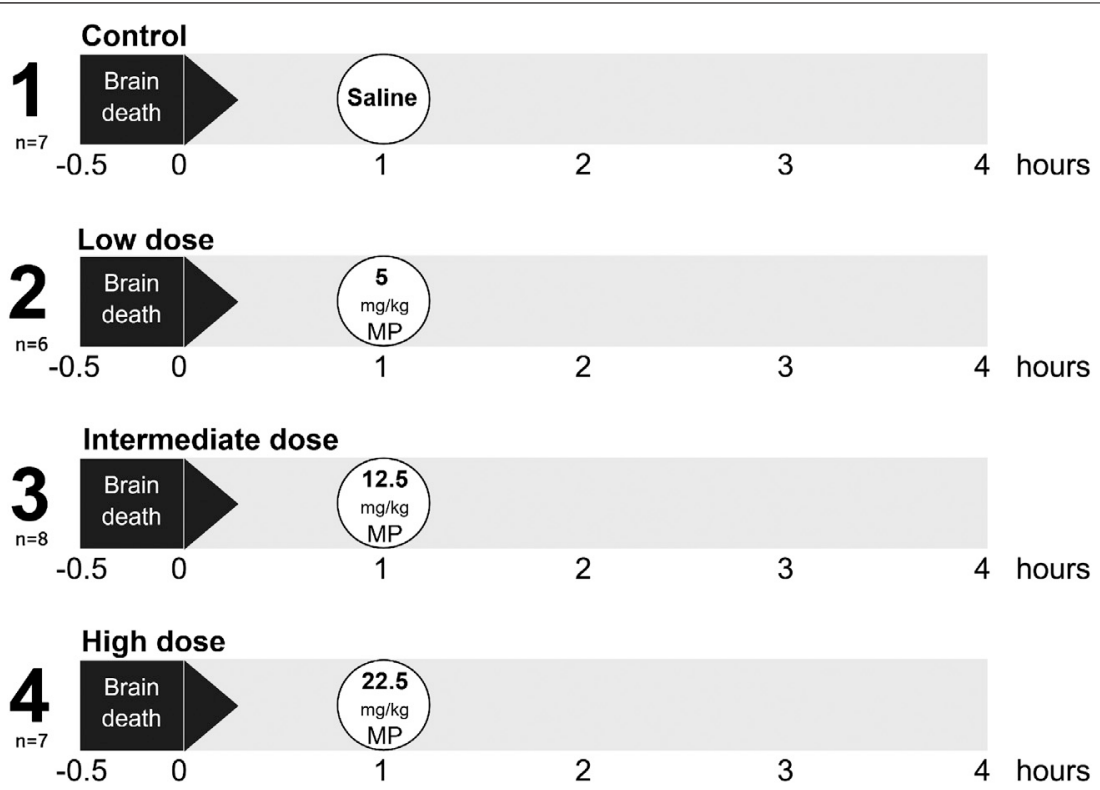

FIGURE 1 | Experimental outline of the study. Rats were randomly assigned to one of four experimental groups, each consisting of $6-8$ rats. Brain death (BD) was induced in all experimental groups, and $1 \mathrm{~h}$ after $\mathrm{BD}$ induction rats were treated intravenously with 1) $0.9 \%$ saline (control, $\mathrm{n}=7$ ), 2) low dose methylprednisolone (MP, $5 \mathrm{mg} / \mathrm{kg}$ of bodyweight (BW), $\mathrm{n}=6$ ), 3) intermediate dose methylprednisolone (12.5 mg/kg of BW, $\mathrm{n}=8$ ) and 4) high dose methylprednisolone (22.5 mg/kg of BW, $\mathrm{n}=7$ ).

TABLE 1 | RT-qPCR primers.

\begin{tabular}{|c|c|c|c|c|}
\hline Primer & Gene & Forward primer & Reverse primer & Amplicon (bp) \\
\hline TNF- $\alpha$ & Tumor necrosis factor- $\alpha$ & AGGCTGTCGCTACATCACTGAA & TGACCCGTAGGGCGATTACA & 67 \\
\hline IL-6 & Interleukin-6 & ССААСТTССААТGСТСТССТААТG & TTCAAGTGCTTCAAGAGTTGGAT & 89 \\
\hline $\mathrm{IL}-1 \beta$ & Interleukin-1 $\beta$ & CAGCAATGGTCGGGACATAGTT & GCATTAGGAATAGTGCAGCCATCT & 75 \\
\hline C3 & Central complement component 3 & CAGCCTGAATGAACGACTAGACA & TCAAAATCATCCGACAGCTCTATC & 96 \\
\hline Cinc-1 & Chemokine (C-X-C motif) ligand-1 & TGGTTCAGAAGATTGTCCAAAAGA & ACGCCATCGGTGCAATCTA & 78 \\
\hline E-sel & E-selectin & GTCTGCGATGCTGCCTACTTG & CTGCCACAGAAAGTGCCACTAC & 73 \\
\hline Ccl-2 (Mcp-1) & Chemokine (C-C motif) ligand-2 & CTITGAATGTGAACTTGACCCATAA & ACAGAAGTGCTTGAGGTGGTTGT & 78 \\
\hline $\mathrm{IL}-10$ & Interleukin-10 & GCAACAGCTCAGCGCATCT & ACAAACTGGTCACAGCTITCGA & 71 \\
\hline $\mathrm{IL}-4$ & Interleukin-4 & CCAGGGTGCTTCGCAAATT & ПTCACCGAGAACCCCAGACTT & 76 \\
\hline
\end{tabular}

the Netherlands). Rats were stabilized for $4 \mathrm{~h}$, after which a laparo-thoracotomy was performed. All organs were flushed with $60 \mathrm{ml} 0.9 \%$ cold saline through the abdominal aorta, after the inferior vena cava was incised for drainage. Lungs were procured and partially snap frozen in liquid nitrogen and partially fixed in formalin and embedded in paraffin.

\section{RT-qPCR}

To assess inflammatory status of donor lungs, gene expression levels were detected by RT-qPCR analyses. TRIzol reagent (Invitrogen Life Technologies, Breda, The Netherlands) was used for isolation of RNA from frozen lung sections. Absence of genomic DNA contamination was verified and integrity was analyzed by gel electrophoresis. Thereafter, cDNA was synthesized according to manufacturer's instructions. Primer sets used for amplifying fragments of several genes are described in Table 1. Amplification and detection of PCR products were performed by the TaqMan Applied Biosystems
7900HT RT-qPCR system (Applied Biosystems, Foster City, United States), measuring SYBR green (Applied Biosystems) emission. Thermal cycling was performed with a hot start for $2 \mathrm{~min}$ on $50^{\circ} \mathrm{C}$, followed by $10 \mathrm{~min}$ on $95^{\circ} \mathrm{C}$. After that, the denaturation step was started with $15 \mathrm{~s}$ at $95^{\circ} \mathrm{C}$ followed by the annealing step and DNA synthesis for $60 \mathrm{~s}$ at $60^{\circ} \mathrm{C}$, which was repeated 40 times. Melt curve analyses were performed to confirm generation of single, specific amplicons. Samples were analyzed in triplicate and house-keeping gene $\beta$-actin was used for normalization of gene expression. Gene expressions were calculated according to the $-\Delta \Delta \mathrm{CT}$ method (Schmittgen and Livak, 2008).

\section{Immunohistochemistry}

Formalin-fixed paraffin embedded lung sections were stained for myeloperoxidase (MPO) to quantify the number of activated neutrophils, and CD68 to investigate macrophage count. After deparaffinization, antigen retrieval was performed 

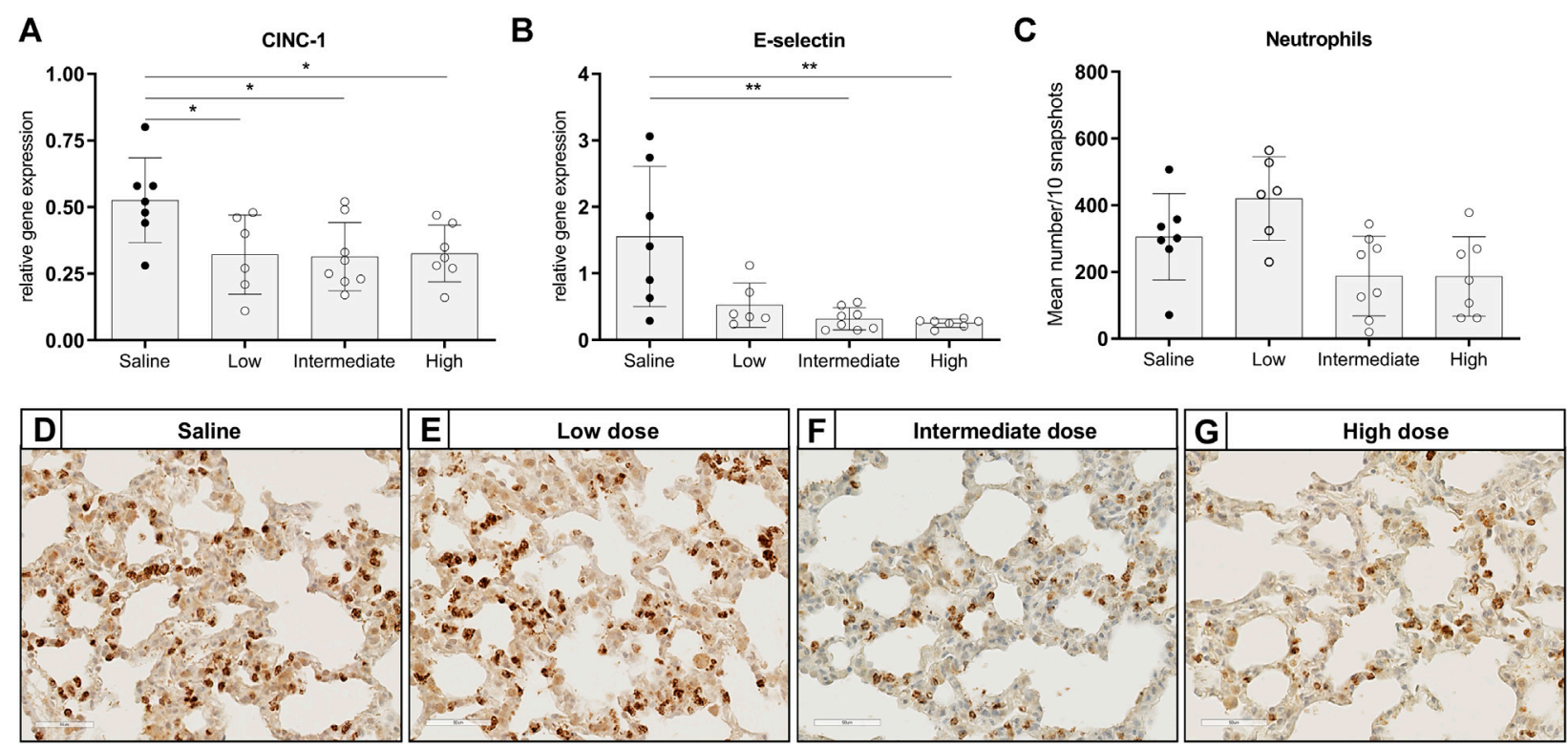

FIGURE 2 | Chemotaxis of neutrophils and infiltration of activated neutrophils in lung tissue. Brain death (BD) was induced in rats assigned to one of four experimental groups, etc. and $1 \mathrm{~h}$ after BD induction rats were treated intravenously with 1) $0.9 \%$ saline (control) 2) low dose methylprednisolone (5 mg/kg of bodyweight (BW), 3) intermediate dose methylprednisolone (12.5 mg/kg of BW) and 4) high dose methylprednisolone (22.5 mg/kg of BW). mRNA gene expression levels of (A) IL8like CINC-1 and (B) E-selectin, involved in chemo-attraction of neutrophils. Data are shown as expressions relative to housekeeping gene $\beta$-actin. (C) Quantification of activated, MPO-stained neutrophils in lung tissue, presented as mean count per 10 random fields. (D-G): Representative snapshots of lung slides stained for MPO. Values are presented as mean \pm SD. ${ }^{*} p<0.05,{ }^{* *} p<0.01$.

with Tris/ $\mathrm{HCl} \quad 0.1 \mathrm{M}$ and sections were blocked with endogenous peroxidase for $30 \mathrm{~min}$. Thereafter, primary antibody MPO $(100 \mu \mathrm{g} / \mathrm{ml}$ Hycult, Uden, The Netherlands) or CD68 antibody (ED-1, $2 \mu \mathrm{g} / \mathrm{ml}$, Bio-Rad, Lunteren, The Netherlands) was incubated for $1 \mathrm{~h}$. Secondary Goat antirabbit (Dako Carpenteria, CA, United States) and rabbit anti-mouse (Dako) horseradish peroxidase (HRP)conjugated antibodies were incubated for $30 \mathrm{~min}$. Next, tertiary rabbit anti-mouse and goat anti-rabbit HRPantibodies were incubated for $30 \mathrm{~min}$. All incubations were performed at room temperature and phosphate-buffered saline was used for washing steps. Reaction was developed by $3,3^{\prime}$ diaminobenzidine-peroxidase substrate solution and sections were counterstained with Haematoxylin. ImageJ Software (National Institutes of Health, Bethesda, United States) was used for quantification of cells. Per lung, 10 random snapshots were analyzed on a 400x magnification. Empty or marginal snapshots and snapshots with collapsed or overextended lung tissue were excluded from analyses. Data are presented as mean number of cells/10 snapshots.

\section{Statistics}

Statistical analyses were performed with IBM SPSS Statistics 23 (IBM Corp., Armonk, United States). One-way Analysis of Variance tests were used for multiple comparisons between groups in normally distributed data, followed by post-hoc Bonferroni tests to compare between two groups. In data with skewed distribution, Kruskall-Wallis tests were performed, followed by Mann-Whitney tests to compare between two groups. $p$-values of $<0.05$ were considered statistically significant. Results are presented as mean \pm standard deviation (SD).

\section{RESULTS}

\section{Chemotaxis and Infiltration of Leukocytes in Lung Tissue of Brain-Dead Donors}

To investigate the effect of different doses methylprednisolone on chemotaxis of leukocytes, we measured gene expression levels of IL-8-like Chemokine (C-x-C motif) ligand 1 (CINC1), E-selectin and MCP-1. Additionally, we determined the number of activated neutrophils and macrophages in lung tissue. Expression of CINC-1 and E-selectin, involved in chemo-attraction of neutrophils, were down regulated in methylprednisolone treated brain-dead rats (Figures 2A,B). The effect was significant in all groups, except for E-selectin levels in the low dose treatment group. As for influx of activated neutrophils, a decrease was seen in rats treated with an intermediate or high dose methylprednisolone, although significance was not reached (Figures 2C-G). As for macrophages, gene expression levels of MCP-1 showed significant down regulation in all methylprednisolone treated groups (Figure 3A). Nevertheless, the number of infiltrated macrophages was not significantly affected by methylprednisolone treatment on a histological level (Figures 3B-F). Taken together, these results suggest that methylprednisolone treatment reduces gene expressions of 

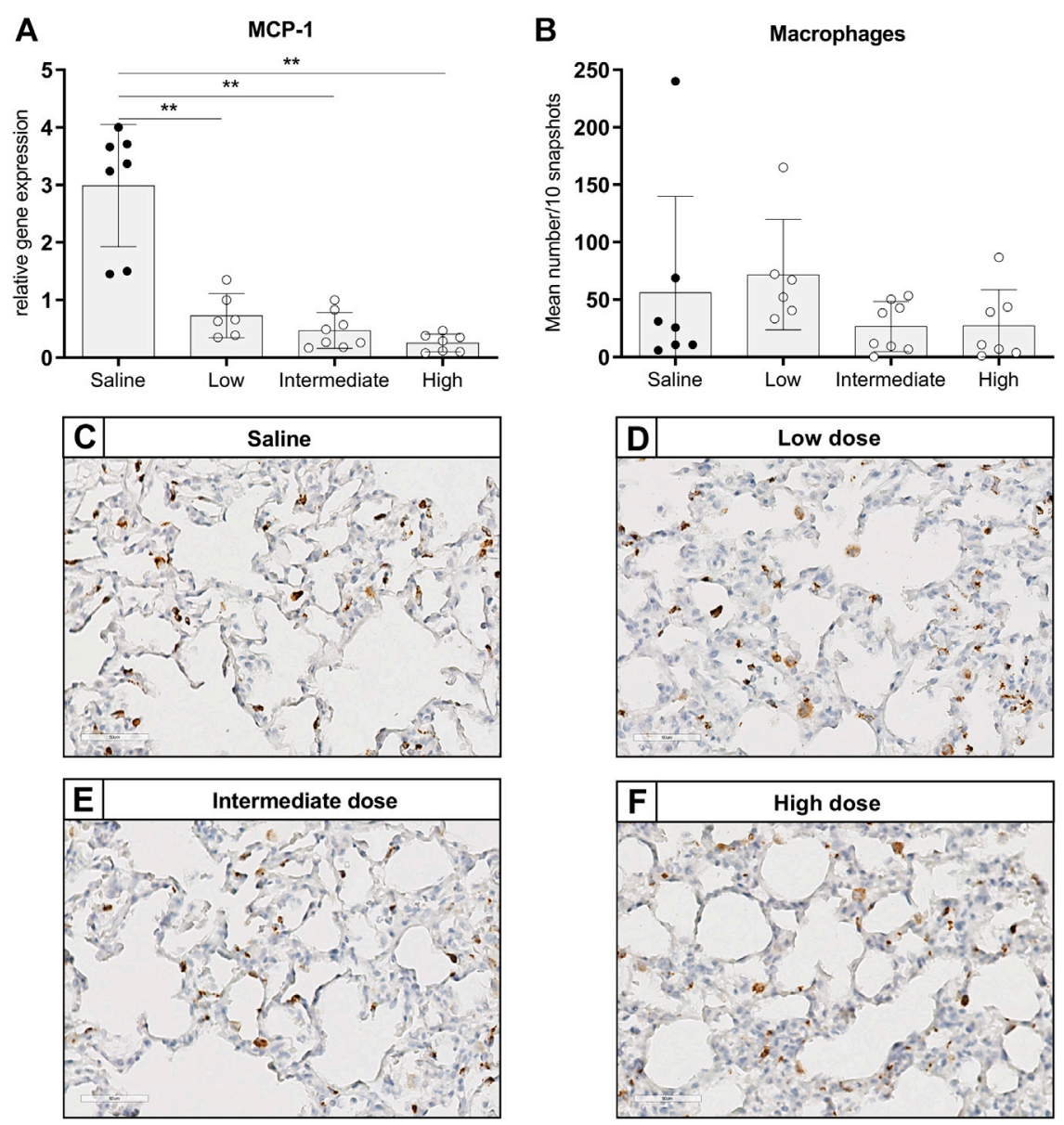

FIGURE 3 | Chemotaxis of macrophages and infiltration of macrophages in lung tissue. Brain death (BD) was induced in rats assigned to one of four experimental groups, etc. and $1 \mathrm{~h}$ after $\mathrm{BD}$ induction rats were treated intravenously with 1) 0.9\% saline (control) 2) low dose methylprednisolone (5 mg/kg of bodyweight (BW), 3) intermediate dose methylprednisolone (12.5 mg/kg of BW) and 4) high dose methylprednisolone (22.5 mg/kg of BW). (A) mRNA gene expression levels of MCP-1, involved in chemo-attraction of macrophages. Data are shown as expressions relative to housekeeping gene $\beta$-actin. (B) Quantification of CD68-stained macrophages in lung tissue, presented as mean count per 10 random fields. (C-F): Representative snapshots of lung slides stained for CD68. Values are presented as mean \pm SD. ${ }^{\star \star} p<0.01$.

chemotactic cytokines for neutrophils and macrophages, primarily in intermediate and high doses.

\section{Pro-inflammatory Gene Expressions in Lung Tissue of Brain-Dead Donors}

The pro-inflammatory state of donor lungs upon treatment with different doses methylprednisolone, was investigated by RTqPCR analyses in lung tissue. In all methylprednisolone treated groups, gene expressions of TNF- $\alpha$, IL- 6 and IL- $1 \beta$ were attenuated compared to the saline treated control group (Figures 4A-C). Activation of the complement system has previously been described in BD-induced organ damage (Damman et al., 2011). To investigate whether methylprednisolone affected the complement system, we assessed central complement component $\mathrm{C} 3$ gene expression levels. No significant differences were seen in C3 gene expression levels between the saline treated control group and the methylprednisolone treated groups (Figure 4D). Collectively, these results indicate that methylprednisolone treatment downregulates pro-inflammatory cytokine expression, but does not involve the complement system.

\section{Anti-inflammatory Gene Expressions in Lung Tissue of Brain-Dead Donors}

Gene expressions of IL-10 and IL-4, traditionally known to be involved in immunoregulating functions, were measured to investigate whether different doses methylprednisolone affects gene expression levels of anti-inflammatory cytokines (Hart et al., 1989; Moore et al., 1993). Gene expression levels of IL-10 in lung tissue were significantly higher in rats treated with intermediate and high doses methylprednisolone, than IL-10 gene expression levels in the saline control group (Figure 5A). In contrast, a decrease in IL-4 expression was seen in all methylprednisolone treated groups (Figure 5B). These results suggest that intermediate and high 

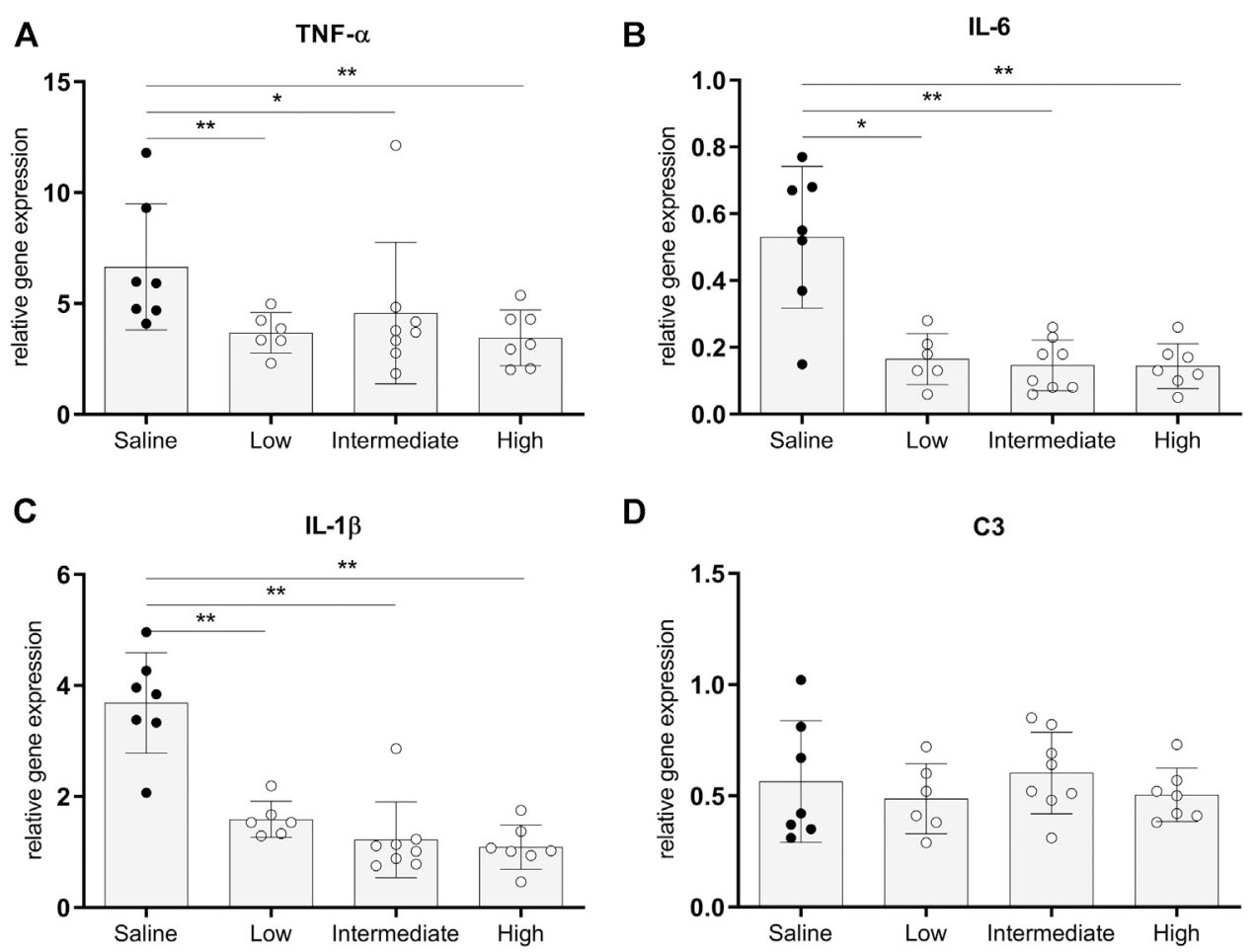

FIGURE 4 | Pro-inflammatory gene expressions in lung tissue. Brain death (BD) was induced in rats assigned to one of four experimental groups, etc. and 1 h after $\mathrm{BD}$ induction rats were treated intravenously with 1) $0.9 \%$ saline (control) 2) low dose methylprednisolone (5 mg/kg of bodyweight (BW), 3) intermediate dose methylprednisolone (12.5 mg/kg of BW) and 4) high dose methylprednisolone (22.5 mg/kg of BW). mRNA gene expression levels of (A) TNF- $\alpha$, (B) IL-6, (C) IL-1 $\beta$ and (D) C3. Data are shown as expressions relative to housekeeping gene $\beta$-actin. Values are presented as mean \pm SD. ${ }^{\star} p<0.05$, ${ }^{\star *} p<0.01$.
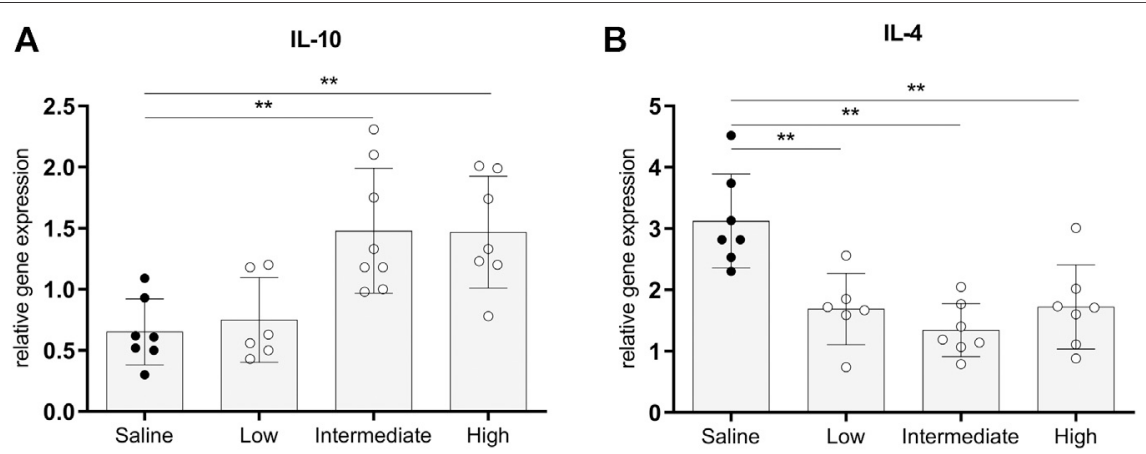

FIGURE 5 |Anti-inflammatory gene expressions in lung tissue. Brain death (BD) was induced in rats assigned to one of four experimental groups, etc. and $1 \mathrm{~h}$ after $\mathrm{BD}$ induction rats were treated intravenously with 1) $0.9 \%$ saline (control) 2) low dose methylprednisolone (5 mg/kg of bodyweight (BW), 3) intermediate dose methylprednisolone (12.5 mg/kg of BW) and 4) high dose methylprednisolone (22.5 mg/kg of BW). mRNA gene expression levels of (A) IL-10 and (B) IL-4. Data are shown as expressions relative to housekeeping gene $\beta$-actin. Values are presented as mean \pm SD. ${ }^{* *} p<0.01$.

doses methylprednisolone induce an IL-10 mediated, antiinflammatory shift in lungs from brain-dead donors.

\section{DISCUSSION}

Methylprednisolone treatment of the potential lung donor is recommended in most clinical protocols, in an attempt to improve lung function and increase organ procurement rates. However, the applied doses vary between centers, which suggests that methylprednisolone treatment guidelines can be optimized in terms of dosing (Dupuis et al., 2014). Dhar et al. suggested that the methylprednisolone dose regimen should be further studied, and investigated the effect of methylprednisolone dose on lung function and organ procurement rate. In the mentioned study, a fixed, low-dose regimen of $300 \mathrm{mg}$ hydrocortisone was compared 
to a higher dose of $15 \mathrm{mg} / \mathrm{kg}$ methylprednisolone in human donors. They showed that the lower dose of $300 \mathrm{mg}$ hydrocortisone led to similar lung function and lung procurement rates, when compared to the higher dose regimen (Dhar et al., 2013). The immunoregulatory effect of methylprednisolone doses on pulmonary immune status was not studied. In this study, we aimed to investigate the effect of three different doses methylprednisolone on the BD-induced inflammatory response, in a rat model for BD. We showed that an intermediate dose of $12.5 \mathrm{mg} / \mathrm{kg}$ methylprednisolone reduces BD-induced lung inflammation and additionally promotes a protective, anti-inflammatory response.

We first studied the effect of different doses methylprednisolone on chemotaxis of leukocytes on a gene expression level. All three doses methylprednisolone reduced gene expression levels of potent chemoattractants for neutrophils and macrophages, reflected by lower IL-8like CINC-1, E-selectin and MCP-1 gene expression levels. Nevertheless, no significance was reached in reduced neutrophil count, although a trend was observed upon treatment with intermediate and high doses methylprednisolone. Earlier studies investigated an even higher treatment dose of $30 \mathrm{mg} / \mathrm{kg}$ methylprednisolone in brain-dead rats. Also in these studies, the amount of neutrophils was not affected by methylprednisolone treatment, even when methylprednisolone was administered shortly after BD induction (Pilla et al., 2013; Felipe Lopes Araujo et al., 2014). Based on these observations, we speculate that methylprednisolone treatment minimally affects donor-derived neutrophils, which are immediately attracted to the site of damage upon BD. However in contrast, reduced neutrophil chemo-attractants may have a forthcoming beneficial effect on recipient-derived neutrophil infiltration, as described by Paulus et al. In the mentioned study, lungs were flushed with $12 \mathrm{mg} / \mathrm{kg}$ methylprednisolone before preservation, which reduced neutrophil infiltration after lung transplantation (Paulus et al., 2013).

Along with the amount of neutrophils in lung tissue, macrophage count was not affected upon treatment with different doses methylprednisolone. However, the present tissue macrophages may shift from a cytotoxic (M1) to a more anti-inflammatory (M2) phenotype, which contributes to a downregulating effect on pro-inflammatory response. We first studied the effect of methylprednisolone on pro-inflammatory mediators, which may be downregulated through inhibition of NF- $\kappa B$ (Rhen and Cidlowski, 2005). Indeed, in line with previous studies in which $30 \mathrm{mg} / \mathrm{kg}$ methylprednisolone was administered, we show a strong, downregulating effect of all doses methylprednisolone on TNF- $\alpha$, IL-6 and IL-1 $\beta$ gene expressions, cytokines that may be secreted by M1 macrophages (Pilla et al., 2013; Felipe Lopes Araujo et al., 2014). In addition, glucocorticoids such as methylprednisolone are described to stimulate polarization from $\mathrm{M} 1$ to the $\mathrm{M} 2 \mathrm{c}$ subset of M2 macrophages, which are described to secrete the antiinflammatory cytokine IL-10 (John et al., 1998; Roszer, 2015). Our results are in line with previously described immunoregulatory effects of methylprednisolone through IL-10, although an upregulation of IL-10 was only observed in rats treated with intermediate and high doses methylprednisolone (Park-Min et al., 2005; Paulus et al., 2013). Hence, intermediate and high doses methylprednisolone may stimulate M2 polarization through the M2c subset of M2 macrophages. In addition, Paulus et al. described an upregulation of IL-4 expression upon methylprednisolone treatment. In the mentioned study, the effect of methylprednisolone pretreatment on the immune response was investigated, measured at $48 \mathrm{~h}$ after lung transplantation (Paulus et al., 2013). The cytokine IL-4 is described to stimulate polarization to the M2a subset of M2 macrophages, which may subsequently lead to secretion of the anti-inflammatory cytokine IL-10 (Roszer, 2015). However in our study, IL-4 expression was decreased in all methylprednisolone treated groups, when compared to the saline treated control group. The controversial effects of corticosteroids on IL-4 expression have previously been illustrated, and are suggested to be the result of direct $v s$. indirect effects of corticosteroids on target cells (Daynes and Araneo, 1989; Wu et al., 1991; Masuyama et al., 1994; Snijdewint et al., 1995; Ramírez et al., 1996; Gratchev et al., 2008). On a short term, corticosteroids might directly inhibit cytokine synthesis in both Th1 and Th2-cells, such as IL-4. However on a longer term, corticosteroids downregulate IL-12 production by macrophages, which might indirectly stimulate IL4 production (Blotta et al., 1997). Our study represents a snapshot at only $4 \mathrm{~h}$ after induction of BD. Therefore, we speculate that the results on IL-4 expression in our study reflect a short-term, inhibiting effect of methylprednisolone, and M2 polarization through the M2a subset is thereby not evident in our model.

The BD-induced inflammatory response in donor lungs is an important target, since the postoperative inflammatory status in transplanted lungs is described to be associated with long-term outcome (Hall et al., 2012). Nevertheless, despite that methylprednisolone treatment is recommended in various donor management protocols, the benefit of methylprednisolone has not yet been irrefutably proven. Duipuis et al. concluded in their review that the current clinical evidence is conflicting and of poor quality, which is partially due to the lack of homogeneous data. In addition, interacting factors such as simultaneous administration of other hormonal therapies, complicate research on the clinical effect of corticosteroids in donor management. For that reason, we emphasize the importance of fundamental research in the search for the significance of methylprednisolone treatment on BD-induced injury. We consider our rat model for $\mathrm{BD}$ as the strong point of our study, which allows us to investigate the effect of different doses methylprednisolone on $\mathrm{BD}$-induced lung damage alone. Based on our results, we consider the intermediate dose of $12.5 \mathrm{mg} / \mathrm{kg}$ methylprednisolone as most suitable to target $\mathrm{BD}$-induced lung inflammation, since both the pro-inflammatory response was reduced and an additional anti-inflammatory response was promoted. The high dose of $22.5 \mathrm{mg} / \mathrm{kg}$ showed no additional beneficial effect, which suggests that the maximum effect has been achieved with an intermediate dose methylprednisolone. Besides that, possible negative effects of high doses methlyprednisolone should be carefully considered. High doses methylprednisolone might dysregulate blood glucose levels in organ donors, which negatively effects organ retrieval rate and graft function (Blasi-Ibanez et al., 2009; Sally et al., 2014). In addition, the effect of methylprednisolone on other potential donor organs should be taken into account. Rebolledo et al. 
studied the effect of different doses methylprednisolone on the quality of donor livers and kidneys, and showed that a high dose of $22.5 \mathrm{mg} / \mathrm{kg}$ showed no additional beneficial effect compared to an intermediate dose of $12.5 \mathrm{mg} / \mathrm{kg}$ methylprednisolone. Thereby, $22.5 \mathrm{mg} / \mathrm{kg}$ methylprednisolone even correlated with higher liver tissue injury markers, which possibly reflects reduced quality of the donor liver (Rebolledo et al., 2015).

The recommended methylprednisolone dose of $12.5 \mathrm{mg} / \mathrm{kg}$ for rats in our study, might be close to doses previously investigated in human studies. However, it should be noted that extrapolation of the optimal treatment dose from rats to humans should be carefully performed, given the biological differences between species. Scaling of dose based on body weight might be insufficient, due to differences in body surface area and pharmacokinetics (Reigner and Blesch, 2002). In a retrospective study by Folette et al., human donors subjected to $14.5 \mathrm{mg} / \mathrm{kg}$ methylprednisolone were compared to untreated controls. The authors concluded that methylprednisolone treatment of the organ donor led to better oxygenation ratios and higher procurement rates (Follette et al., 1998). In addition, Nath et al. showed increased lung procurement rates when donors were treated with $15 \mathrm{mg} / \mathrm{kg}$ methylprednisolone (Nath et al., 2010). In a randomized-controlled study, Venkateswaran et al. compared donor treatment with $15 \mathrm{mg} / \mathrm{kg}$ methylprednisolone to untreated controls, etc. and found less pumonary edema and higher suitability of donor lungs, despite no differences in oxygenation ratio (Venkateswaran et al., 2008). More recently, Dhar et al. compared donor treatment of $15 \mathrm{mg} / \mathrm{kg}$ methlyprednisolone to a fixed, low dose of $300 \mathrm{mg}$ hydrocortisone, which corresponds to a dose of $<1 \mathrm{mg} / \mathrm{kg}$ methylprednisolone for a $70-\mathrm{kg}$ donor. In the mentioned study, they did not find differences between lung procurement rates or donor lung function, suggesting that lower corticosteroid doses might be sufficient in donor management (Dhar et al., 2013). Yet, the beforementioned studies did not specifically focus on the effect of methylprednisolone dose on pulmonary inflammation elicited by the pathophysiology of BD. Nevertheless, speculations may be drawn from other disease models, such as acute respiratory stress syndrome (ARDS). Early ARDS is characterized by diffuse alveolar injury, lung edema and neutrophil-mediated inflammation, which resembles the pathophysiology of BD-induced lung damage. An early study by Bernard et al. in 1987 showed no improvement in mortality or ventilatory characteristics when patients were treated with high doses methylprednisolone of $30 \mathrm{mg} / \mathrm{kg}$ every $6 \mathrm{~h}$, possibly due to suppression of HPA axis and higher risk of infection (Bernard et al., 1987). A recent retrospective and observational study confirmed that high dose methylprednisolone may not be suitable for patients with ARDS, by showing increased mortality rates in ARDS patients treated with high dose methylprednisolone (defined as $>500 \mathrm{mg}$ methylprednisolone/day) compared to the non-high-dose group (Kido et al., 2018). In contrast, studies investigating low-dose methylprednisolone $(1 \mathrm{mg} / \mathrm{kg} /$ day $)$ showed reduced mortality and duration of mechanical ventilation in patients with early ARDS, after treatment for several weeks (Meduri et al., 2007). In addition, patients with unresolving ARDS treated with $2 \mathrm{mg} / \mathrm{kg} /$ day methylprednisolone showed obvious reductions in TNF-a, IL-1 $\beta$ and IL-6 serum levels, after 4 weeks of treatment (Meduri et al., 1998). However, the effect of low-dose methlyprednisolone treatment on anti-inflammatory cytokines was not addressed. Whether low doses of $1-2 \mathrm{mg} / \mathrm{kg}$ methylprednisolone are sufficiently adequate to both downregulate the pro-inflammatory response and stimulate an anti-inflammatory response in human brain-dead donors as observed in our rat model, requires further clinical investigation. In addition, it should be noted that the beforementioned doses in the treatment of ARDS are administered over several weeks, while the time frame of donor mangement is closer to several hours or days.

Data from laboratory animal models can be of exceptional value, since pathophysiological mechanisms may be difficult to test in humans, while animal models provide more experimental possibilities. Nevertheless, even though BD-induced lung damage and inflammation were reliably reprodcued in our rat model, it is impossible to reproduce all the characteristics of the human lung transplantation process in an animal model. The whole chain of events in human lung donation- and transplantation is highly complex due to many confounding factors. In our study we did not investigate the effect of different doses methylprednisolone on ischemia-reperfusion injury, since transplantation of donor lungs was not included in our model. Hence, the possible longer-term immunomodulatory effects of different doses methylprednisolone, in presence of circulating recipient-derived leukocytes, requires attention in future studies.

This study provides a foundation for further research on methylprednisolone regimens and $\mathrm{BD}$-induced lung inflammation. We conclude from this study that an intermediate dose of $12.5 \mathrm{mg} / \mathrm{kg}$ methylprednisolone is the optimal treatment dose for BD-induced lung inflammation in rats, which reduces the pro-inflammatory state and additionally promotes a protective, anti-inflammatory response.

\section{DATA AVAILABILITY STATEMENT}

The raw data supporting the conclusions of this article will be made available by the authors, without undue reservation.

\section{ETHICS STATEMENT}

The animal study was reviewed and approved by the Institutional Animal Care and Use Committee of the University of Groningen (IACUC-RUG).

\section{AUTHOR CONTRIBUTIONS}

JZ: Participated in research design, laboratory analyses, data analyses and writing of the paper. $\mathrm{NH}$ : Participated in research design and supervised the study and writing of the paper. PO: Participated in performing animal operations and laboratory analyses. BL: Participated in research design and performing animal operations. RR: Participated in research design and performing animal operations. ME: Participated in research design and supervised the study and writing of the paper. HL: Participated in research design and supervised the study and writing of the paper. 


\section{REFERENCES}

Animal Welfare Body Utrecht (2017). Act of 12 January 1977, concerning rules relating to scientific procedures on animals. Utrecht, Netherlands: Animal Welfare Body Utrecht.

Avlonitis, V. S., Fisher, A. J., Kirby, J. A., and Dark, J. H. (2003). Pulmonary Transplantation: the role of brain death in donor lung injury. Transplantation 75, 1928-1933. doi:10.1097/01.TP.0000066351.87480.9E

Bernard, G. R., Luce, J. M., Sprung, C. L., Rinaldo, J. E., Tate, R. M., Sibbald, W. J., et al. (1987). High-dose corticosteroids in patients with the adult respiratory distress syndrome. N. Engl. J. Med. 317, 1565-1570. doi:10.1056/ nejm198712173172504

Blasi-Ibanez, A., Hirose, R., Feiner, J., Freise, C., Stock, P. G., Roberts, J. P., et al. (2009). Predictors associated with terminal renal function in deceased organ donors in the intensive care unit. Anesthesiology 110, 333-341. doi:10.1097/ ALN.0b013e318194ca8a

Blotta, M. H., DeKruyff, R. H., and Umetsu, D. T. (1997). Corticosteroids inhibit IL-12 production in human monocytes and enhance their capacity to induce IL4 synthesis in CD4+ lymphocytes. J. Immunol. 158, 5589-5595.

Cooper, D. K., Novitzky, D., and Wicomb, W. N. (1988). Hormonal therapy in the brain-dead experimental animal. Transpl. ProcTransplant. Proc. 20, 51-54.

Cooper, D. K., Novitzky, D., and Wicomb, W. N. (1989). The pathophysiological effects of brain death on potential donor organs, with particular reference to the heart. Ann. R. Coll. Surg. Engl. 71, 261-266.

Cypel, M., Levvey, B., Van Raemdonck, D., Erasmus, M., Dark, J., Love, R., et al. (2015). International society for heart and lung transplantation donation after circulatory death registry report. J. Heart Lung Transpl. 34, 1278. doi:10.1016/j. healun.2015.08.015

Damman, J., Seelen, M. A., Moers, C., Daha, M. R., Rahmel, A., Leuvenink, H. G., et al. (2011). Systemic complement activation in deceased donors is associated with acute rejection after renal transplantation in the recipient. Transplantation 92, 163-169. doi:10.1097/TP.0b013e318222c9a0

Daynes, R. A., and Araneo, B. A. (1989). Contrasting effects of glucocorticoids on the capacity of $\mathrm{T}$ cells to produce the growth factors interleukin 2 and interleukin 4. Eur. J. Immunol. 19, 2319-2325. doi:10.1002/eji.1830191221

Dhar, R., Cotton, C., Coleman, J., Brockmeier, D., Kappel, D., Marklin, G., et al. (2013). Comparison of high- and low-dose corticosteroid regimens for organ donor management. J. Crit. Care 28, 1117. doi:10.1016/j.jcrc.2012.04.015

Dupuis, S., Amiel, J. A., Desgroseilliers, M., Williamson, D. R., Thiboutot, Z., Serri, K., et al. (2014). Corticosteroids in the management of brain-dead potential organ donors: a systematic review. Br. J. Anaesth. 113, 346-359. doi:10.1093/ bja/aeu154

Felipe Lopes Araujo, L., Arthur Rodrigo Ronconi Holand, I., Artur de Oliveira Paludo, I., É verton Franco Silva, I., Luiz Alberto Forgiarini Junior, I., Luiz Felipe Forgiarini, I., et al. (2014). Effect of the systemic administration of methylpred- nisolone on the lungs of brain-dead donor rats undergoing pulmonary transplantation. Clinics (Sao Paulo) 69, 129-133. doi:10.6061/ clinics/2014(02)09

Follette, D. M., Rudich, S. M., and Babcock, W. D. (1998). Improved oxygenation and increased lung donor recovery with high-dose steroid administration after brain death. J. Heart Lung Transpl. 17, 423-429. doi:10.6061/clinics/2014(02)09

Gratchev, A., Kzhyshkowska, J., Kannookadan, S., Ochsenreiter, M., Popova, A., $\mathrm{Yu}, \mathrm{X}$., et al. (2008). Activation of a TGF-beta-specific multistep gene expression program in mature macrophages requires glucocorticoid-mediated surface expression of TGF-beta receptor II. J. Immunol. 180, 6553-6565. doi:10. 4049/jimmunol.180.10.6553

Hall, D. J., Baz, M., Daniels, M. J., Staples, E. D., Klodell, C. T., Moldawer, L. L., et al. (2012). Immediate postoperative inflammatory response predicts long-term outcome in lung-transplant recipients. Interact. Cardiovasc. Thorac. Surg. 15, 603-607. doi:10.1093/icvts/ivs330

Hart, P. H., Vitti, G. F., Burgess, D. R., Whitty, G. A., Piccoli, D. S., and Hamilton, J. A. (1989). Potential antiinflammatory effects of interleukin 4: suppression of human monocyte tumor necrosis factor alpha, interleukin 1, and prostaglandin E2. Proc. Natl. Acad. Sci. U.S.A. 86, 3803-3807. doi:10.1073/pnas.86.10.3803

John, M., Lim, S., Seybold, J., Jose, P., Robichaud, A., O'Connor, B., et al. (1998). Inhaled corticosteroids increase interleukin-10 but reduce macrophage inflammatory protein-1alpha, granulocyte-macrophage colony-stimulating factor, and interferon-gamma release from alveolar macrophages in asthma. Am. J. Respir. Crit. Care Med. 157, 256-262. doi:10.1164/ajrccm.157.1.9703079

Kido, T., Muramatsu, K., Asakawa, T., Otsubo, H., Ogoshi, T., Oda, K., et al. (2018). The relationship between high-dose corticosteroid treatment and mortality in acute respiratory distress syndrome: a retrospective and observational study using a nationwide administrative database in Japan. BMC Pulm. Med. 18, 28. doi:10.1186/s12890-018-0597-5

Liu, T., Clark, R. K., McDonnell, P. C., Young, P. R., White, R. F., Barone, F. C., et al. (1994). Tumor necrosis factor-alpha expression in ischemic neurons. Stroke 25, 1481-1488. doi:10.1161/01.str.25.7.1481

Liu, T., McDonnell, P. C., Young, P. R., White, R. F., Siren, A. L., Hallenbeck, J. M., et al. (1993). Interleukin-1 beta mRNA expression in ischemic rat cortex. Stroke 24, 1746-1751. doi:10.1161/01.str.24.11.1746

Lu, J., Goh, S. J., Tng, P. Y., Deng, Y. Y., Ling, E. A., and Moochhala, S. (2009). Systemic inflammatory response following acute traumatic brain injury. Front. Biosci. (Landmark Ed.) 14, 3795-3813. doi:10.2741/3489

Masuyama, K., Jacobson, M. R., Rak, S., Meng, Q., Sudderick, R. M., Kay, A. B., et al. (1994). Topical glucocorticosteroid (fluticasone propionate) inhibits cells expressing cytokine mRNA for interleukin- 4 in the nasal mucosa in allergeninduced rhinitis. Immunology 82, 192-199.

McKeating, E. G., Andrews, P. J., Signorini, D. F., and Mascia, L. (1997). Transcranial cytokine gradients in patients requiring intensive care after acute brain injury. Br. J. Anaesth. 78, 520-523. doi:10.1093/bja/78.5.520

Meduri, G. U., Golden, E., Freire, A. X., Taylor, E., Zaman, M., Carson, S. J., et al. (2007). Methylprednisolone infusion in early severe ards: results of a randomized controlled trial. Chest 131, 954-963. doi:10.1378/chest.062100

Meduri, G. U., Headley, A. S., Golden, E., Carson, S. J., Umberger, R. A., Kelso, T., et al. (1998). Effect of prolonged methylprednisolone therapy in unresolving acute respiratory distress syndrome: a randomized controlled trial. JAMA 280, 159-165. doi:10.1001/jama.280.2.159

Moore, K. W., O'Garra, A., de Waal Malefyt, R., Vieira, P., and Mosmann, T. R. (1993). Interleukin-10. Аnnu. Rev. Immunol. 11, 165-190. doi:10.1146/ annurev.iy.11.040193.001121

Nath, D. S., Ilias Basha, H., Liu, M. H., Moazami, N., and Ewald, G. A. (2010). Increased recovery of thoracic organs after hormonal resuscitation therapy. J. Heart Lung Transpl. 29, 594-596. doi:10.1016/j.healun.2009.12.001

Neyrinck, A., Raemdonck, D. V., and Monbaliu, D. C. (2013). URRENT OPINION Donation after circulatory death: current status. Curr. Opin. Anaesthesiol 26, 382-390. doi:10.1097/ACO.0b013e328360dc87

Offner, H., Subramanian, S., Parker, S. M., Afentoulis, M. E., Vandenbark, A. A., and Hurn, P. D. (2006). Experimental stroke induces massive, rapid activation of the peripheral immune system. J. Cereb. Blood Flow Metab. 26, 654-665. doi:10.1038/sj.jcbfm.9600217

Park-Min, K. H., Antoniv, T. T., and Ivashkiv, L. B. (2005). Regulation of macrophage phenotype by long-term exposure to IL-10. Immunobiology 210, 77-86. doi:10.1016/j.imbio.2005.05.002

Paulus, P., Holfeld, J., Urbschat, A., Mutlak, H., Ockelmann, P. A., Tacke, S., et al. (2013). Prednisolone as preservation additive prevents from ischemia reperfusion injury in a rat model of orthotopic lung transplantation. PLoS One 8, e73298. doi:10.1371/journal.pone.0073298

Pilla, E. S., Pereira, R. B., Forgiarini Junior, L. A., Forgiarini, L. F., Paludo, Ade. O., Kulczynski, J. M., et al. (2013).Effects of methylprednisolone on inflammatory activity and oxidative stress in the lungs of brain-dead rats. J. Bras. Pneumol. 39, 173-180. doi:10.1590/S1806-37132013000200008

Rahmel, A. (2013). Annual report 2013. Available at: http://www.eurotransplant. $\mathrm{org} / \mathrm{cms} /$ mediaobject.php?file=AR20135.pdf (Accessed May 4, 2018).

Ramírez, F., Fowell, D. J., Puklavec, M., Simmonds, S., and Mason, D. (1996). Glucocorticoids promote a TH2 cytokine response by CD4+ T cells in vitro. J. Immunol. 156, 2406-2412.

Rebolledo, R. A., Liu, B., Akhtar, M. Z., Ottens, P. J., Zhang, J., Ploeg, R. J., et al. (2015). Steroid anti-inflammatory effects did not improve organ quality in brain-dead rats. Biomed. Res. Int., 2015, 207534. doi:10.1155/ 2015/207534

Reigner, B. G., and Blesch, K. (2002). Estimating the starting dose for entry into humans: Principles and practice. Eur. J. Clin. Pharmacol. 57, 835-845. doi:10. 1007/s00228-001-0405-6 
Rhen, T., and Cidlowski, J. A. (2005). Antiinflammatory action of glucocorticoids-new mechanisms for old drugs. N. Engl. J. Med. 353, 1711-1723. doi:10.1056/ NEJMra050541

Roszer, T. (2015). Understanding the mysterious M2 macrophage through activation markers and effector mechanisms. Mediators Inflamm. 2015, 816460. doi:10.1155/2015/816460

Sally, M. B., Ewing, T., Crutchfield, M., Patel, M. S., Raza, S., De La Cruz, S., et al. (2014). Determining optimal threshold for glucose control in organ donors after neurologic determination of death: a United Network for Organ Sharing Region 5 Donor Management Goals Workgroup prospective analysis. J. Trauma. Acute. Care Surg. 76 (62-8), 62. doi:10.1097/TA.0b013e3182ab0d9b

Schmittgen, T. D., and Livak, K. (2008). Analyzing real-time PCR data by the comparative C(T) method. Nat. Protoc. 3, 1101-1108. doi:10.1038/nprot. 2008.73

Snijdewint, F. G., Kapsenberg, M. L., Wauben-Penris, P. J., and Bos, J. D. (1995). Corticosteroids class-dependently inhibit in vitro Th1- and Th2-type cytokine production. Immunopharmacology 29, 93-101. doi:10.1016/0162-3109(94) 00048-k

Venkateswaran, R. V., Patchell, V. B., Wilson, I. C., Mascaro, J. G., Thompson, R. D., Quinn, D. W., et al. (2008). Early donor management increases the retrieval rate of lungs for transplantation. Ann. Thorac. Surg. 85, 278-286. doi:10.1016/j. athoracsur.2007.07.092

Wang, X., Yue, T. L., Barone, F. C., White, R. F., Gagnon, R. C., and Feuerstein, G. Z. (1994). Concomitant cortical expression of TNF-alpha and IL-1 beta mRNAs follows early response gene expression in transient focal ischemia. Mol. Chem. Neuropathol. 23, 103-114. doi:10.1007/BF02815404

Wang, X., Yue, T. L., Young, P. R., Barone, F. C., and Feuerstein, G. Z. (1995). Expression of interleukin-6, c-fos, and zif268 mRNAs in rat ischemic cortex. J. Cereb. Blood Flow Metab. 15, 166-171. doi:10.1038/jcbfm.1995.18

Wu, C. Y., Fargeas, C., Nakajima, T., and Delespesse, G. (1991). Glucocorticoids suppress the production of interleukin 4 by human lymphocytes. Eur. J. Immunol. 21, 2645-2647. doi:10.1002/eji.1830211053

Zweers, N., Petersen, A. H., van der Hoeven, J. A., de Haan, A., Ploeg, R. J., de Leij, L. F., et al. (2004). Donor brain death aggravates chronic rejection after lung transplantation in rats. Transplantation 78, 1251-1258. doi:10.1097/01.tp. 0000142679.45418 .96

Conflict of Interest: The authors declare that the research was conducted in the absence of any commercial or financial relationships that could be construed as a potential conflict of interest.

Copyright (c) 2021 Van Zanden, 'T Hart, Ottens, Liu, Rebolledo, Erasmus and Leuvenink. This is an open-access article distributed under the terms of the Creative Commons Attribution License (CC BY). The use, distribution or reproduction in other forums is permitted, provided the original author(s) and the copyright owner(s) are credited and that the original publication in this journal is cited, in accordance with accepted academic practice. No use, distribution or reproduction is permitted which does not comply with these terms. 